National Energy Technology Laboratory

Strategic Center For Natural Gas (SCNG)

\title{
Portable Acoustic Monitoring Package (PAMP) $7^{\text {th }}$ Quarterly Report
}

Reporting Start Date: January 1, 2004

Reporting End Date: March 30, 2004

Principle Authors:

John L. Loth (304) 293-4111 ext 2343

jloth@mail.wvu.edu

Gary J. Morris (304) 293-4111 ext 2342

gmorris@mail.wvu.edu

(Mike) George M. Palmer (304) 293-4111 ext 2342

gmpalmer@mail.wvu.edu

and students:

Richard Guiler and Patrick Browning

Revised Report Issue Date: July 20, 2004

DOE Award Number: DE-FC26-02NT41324

Submitting Organization:

West Virginia University

Department of Mechanical and Aerospace Engineering

G-70 Engineering Sciences Building

Evansdale Drive

Morgantown, WV 26506

SCNG Contact:

Daniel J. Driscoll (304) 285-4717

daniel.driscoll@netl.doe.gov

Industrial Contact:

Brian C. Sheppard (304) 627-3733

Brian_C_Sheppard@dom.com

and

Gregory May (304) 627-3454

c_gregory_may@dom.com

At Dominion Transmission, Inc

Clarksburg, WV 


\section{Portable Acoustic Monitoring Package (PAMP) Table of Contents \\ Abstract \\ Executive Summary \\ I. Introduction \\ II. Experimental \\ A. High Pressure Microphone design and Calibration \\ B. Cataloging Data Acquisition and Management \\ C. Online Acoustic Sensor Calibrator (OASC) \\ D. Final PAMP Configuration and High Pressure Calibration}

\section{Results and Discussion \\ IV. Conclusions}

\section{List of Tables}

Table 1 - TEAC TASCAM PS5 specifications. (Broderson, S., 2003)

\section{List of Figures}

Figure 1 - WVU Portable Acoustic Monitoring Package (PAMP) set up for high-pressure calibrations.

Figure 2 - Optimus model 270-090 microphone wiring diagram.

Figure 3 - Performance comparison between a Standard 270-090 microphone and a Pressure equalized version, both being exposed to the same power and frequency acoustic signal.

Figures $4 \& 5$ - The Teac TASCAM PS-5 with audio inputs and outputs on the top. On the bottom are MIDI In, USB, and AC-adapter ports. Selector switches and the Compact Flash port are on the unit's right side. (Broderson, S., 2003)

Figure 6 - Photograph of OASC installed on PAMP. Each of the blue handled valves are OASCs with different frequency-pressure curves.

Figure 7 - Schematic of PAMP and the high-pressure laboratory apparatus Figure 8 - Equalized and standard Optimus 270-090 microphone frequency response in millivolts vs. line pressure in psig.

Figure 9 - Equalized and standard Optimus 270-090 microphone frequency response in decibels vs. line pressure in psig.

Figure 10 - FFT and raw signal of $521 \mathrm{~Hz}$ signal generated at a constant 350 psig line pressure in Sigview 1.9.1 that has been recorded by the PAMP

Figure 11 - FFT and raw signal of a $983 \mathrm{~Hz}, 114$ DB signal recorded by PAMP from a Textronix sound calibrator G in Sigview 1.9.1 that has been recorded by the PAMP for microphone calibration.

Figure 12 - FFT and raw signal of a $521 \mathrm{~Hz}$ signal generated at constant 350 psig line pressure with simulated leak (1/2" partially open valve) in Sigview 1.9.1 that has been recorded by the PAMP. 
Disclaimer

"This report was prepared as an account of work sponsored by an agency of the United States Government. Neither the United States Government nor any of their employees, makes any warranty, express or implied, or assumes any legal liability or responsibility for the accuracy, completeness, or usefulness any information, apparatus, product, or process disclosed, or represents that its use would not infringe privately owned rights. Reference herein to any specific commercial product, process or service by trade name, trademark, manufacturer, or otherwise does not necessarily constitute or imply its endorsement, recommendation, or favoring by the United States Government or any agency thereof. The views and opinions of the authors expressed herein do not necessarily state or reflect those of the United States Government or any agency thereof." 


\section{Portable Acoustic Monitoring Package (PAMP)}

Abstract (250 words)

The Portable Acoustic Monitoring Package (PAMP) has been designed to record and monitor the acoustic signal in natural gas transmission lines. In particular the three acoustic signals associated with a line leak. The system is portable ( $30 \mathrm{lbs})$ and is designed for line pressures up to 1000 psi. It has become apparent that cataloging of the various background acoustic signals in natural gas transmission line is very important if a system to identify leak signals is to be developed. The low-pressure (0-200 psig) laboratory test phase has been completed and a number of field trials have been conducted. Before the cataloging phase could begin, a few problems identified in field trials identified had to be corrected such as:

1) Decreased microphone sensitivity at line pressures above 250 psig.

2) The inability to deal with large data sets collected when cataloging the variety of signals in a transmission line.

3) The lack of an available online acoustic calibration system.

These problems have been solved and the WVU PAMP is now fully functional over the entire pressure range found in the Natural Gas transmission lines in this region. Field portability and reliability have been greatly improved. Data collection and storage have also improved to the point were the full acoustic spectrum of acoustic signals can be accurately cataloged, recorded and described. 


\section{Executive Summary}

The Portable Acoustic Monitoring Package (PAMP) has been designed to record and monitor the acoustic signal in natural gas transmission lines, in particular the three acoustic signals associated with a line leak. The system is portable ( $\sim 30 \mathrm{lbs})$ and is designed for line pressures up to $1000 \mathrm{psi}$. It has become apparent that cataloging of the various background acoustic signals in natural gas transmission line is very important if a system to identify leak signals is to be developed. The low-pressure (0-200 psig) laboratory test phase has been completed and a number of field trials have been conducted. Before the cataloging phase could begin, a few problems needed to be overcome. Field trials identified some deficiencies in the PAMP design and these are as follows:

- Decreased microphone sensitivity at line pressures above 250 psig.

- The inability to deal with large data sets collected when cataloging the variety of signals in a transmission line.

- The lack of an online acoustic calibration system.

The research focus this quarter has been remedying these problems so that acoustic signal cataloging can begin. The achievements of this past quarter are as follows:

- A new pressure-compensating microphone has been developed, which drastically improves microphone sensitivity at higher pressures.

- A new data acquisition system, which compresses acoustic data files to a MP3 format as used in the audio recording industry has been procured. This allows the recording and efficient storage of large acoustic data files.

- A new signal-processing program capable of reading the compressed file format has been purchased and is currently being used for signal analysis.

- An online acoustic calibration system has been developed and tested. Safety and field portability issues demanded that the generation of a known acoustic signal be accomplished by an electronic device that operated at less than $5 \mathrm{~V}$ DC. This was not practical, therefore a free-reed oscillator type system was designed to generate acoustic signals of known frequency and power. This system uses the natural gas pressure and flow during a controlled gas bleedoff for sensor calibration.

- A laboratory high-pressure (0-1000 psig) testing and calibration system has been developed for the PAMP. 


\section{Introduction}

The Portable Acoustic Monitoring Package (PAMP) has been designed to record and monitor the acoustic signals in natural gas transmission lines, in particular, the three acoustic signals associated with a line leak. The system is portable ( $30 \mathrm{lbs})$ and is designed for line pressures up to $1000 \mathrm{psi}$. It has become apparent that cataloging of the various background acoustic signals in natural gas transmission line is very important if a system to identify leak signals is to be developed. The low-pressure (0-200 psig) laboratory test phase has been completed and a number of field trials have been conducted. Before the cataloging phase could begin, a few problems needed to be overcome. Field trials identified some deficiencies in the PAMP design and these are as follows:

- Decreased microphone sensitivity at line pressures above 250 psig.

- The inability to deal with large data sets collected when cataloging the variety of signals in a transmission line.

- The lack of an online acoustic calibration system.

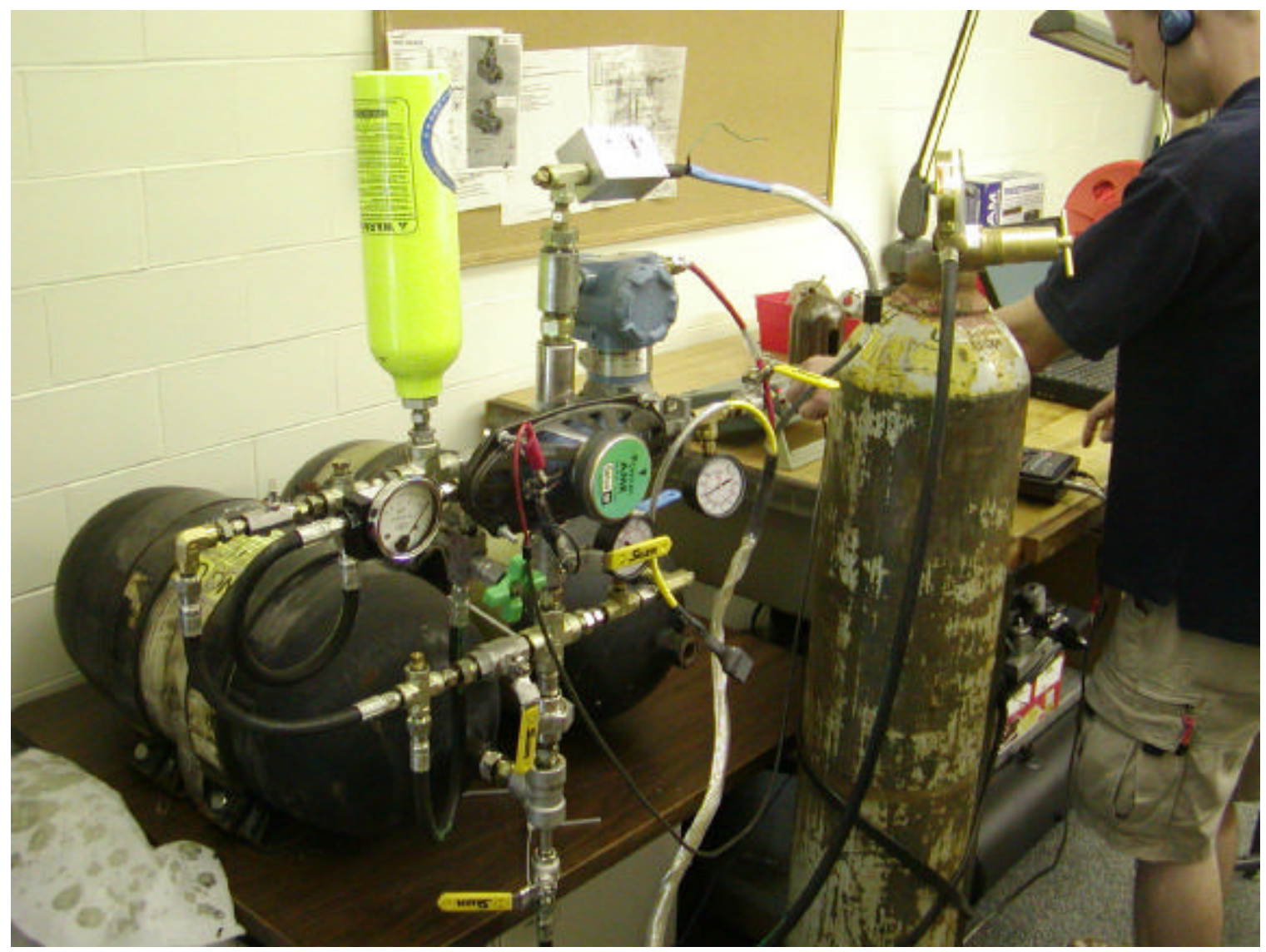

Figure 1 - WVU Portable Acoustic Monitoring Package (PAMP) set up for high-pressure calibrations. 


\section{Experimental}

\section{A. High Pressure Microphone Design and Calibration}

The current PAMP uses a high-quality Optimus model 270-090 omni-directional condenser type microphone. Its wide frequency response is ideal for pipeline acoustic applications. The frequency response is fairly constant between $30 \mathrm{~Hz}$ and $3000 \mathrm{~Hz}$, which is also the frequency range that is most valuable for the monitoring of acoustic signals in natural gas transmission lines.

The microphone is installed inside the PAMP on a 1000 psi three conductor feedthrough. The new feed-through design based on using existing a $3 / 4$ " stainless steel plug with a $9 / 16$ " diameter hole. This plug has a $1 / 2$ " wide chip mounting board bonded to the inside on which the $1 / 2$ " microphone is soldered. The mounting board connects to the outside through three solid copper wires. These wires pass through $1 / 4$ "NPT 3000 psi short nipple, which is filled with a mixture of milled glass fibers and epoxy to form a 1000 psi seal. External connection is achieved through the use of a $1 / 4$ " stereo phone plug. A preamplifier is mounted externally with its power supplied by a 1.55 volt Toshiba: LR44 battery

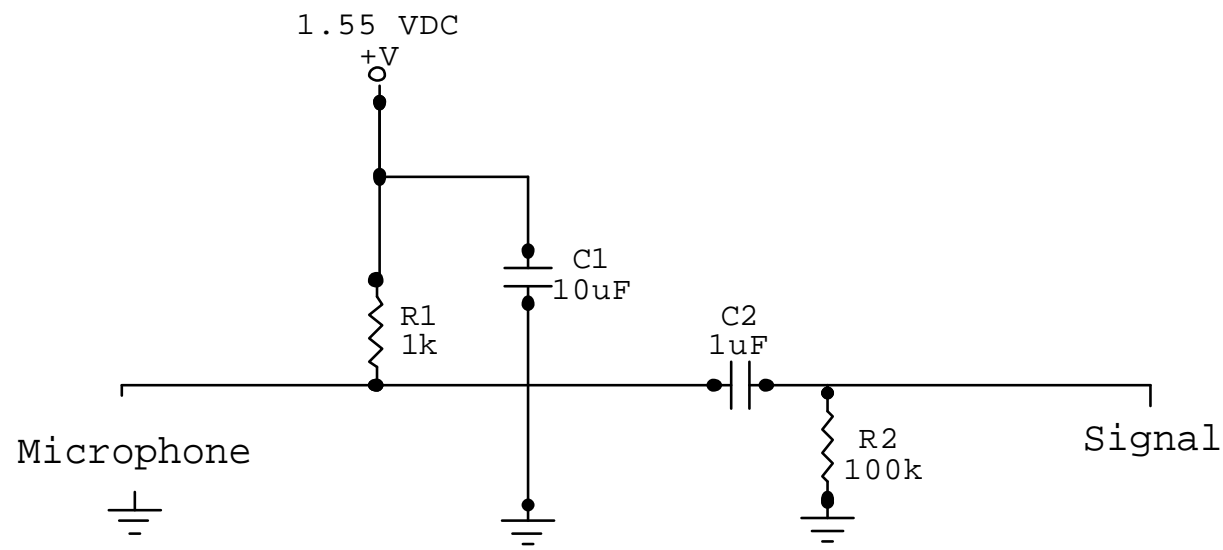

Figure 2 - Optimus model 270-090 microphone wiring diagram.

It has $1 / 4$ " stereophonic male and female connectors on either side of a $1 \frac{1}{2}$ " x $2 \frac{1 / 2}{2}$ " $\mathrm{x}$ 2 " aluminum shielded box with a On/Off switch for the 1.55 volt preamplifier power. The Optimus 270-090 microphone performed well in laboratory experiments with line pressures up to $200 \mathrm{psig}$. It became apparent during higher-pressure field tests that performance dropped off drastically. 
Once a high-pressure laboratory test apparatus was developed (Figure 1) a pressure compensated microphone was developed. Through a number of experiments a design developed which uses the original Optimus 270-090 microphone with a 0.022 inch diameter pressure equalization hole. The pressure equalization hole is drilled directly behind the microphones diaphragm. The pressure equalized microphone performed well up to 1000 psig and calibration test will be discussed in the results and discussion section.

The PAMP microphone is calibrated using a Textronix model CF6250 signal generator and a $10 \mathrm{Ohm}$ driver mounted to the plumbing tree. A sinusoidal $450 \mathrm{~Hz}$ constant power signal is generated. Then at various line pressures up to $1000 \mathrm{psig}$ a FFT of the microphone output is taken. The power of the $450 \mathrm{~Hz}$ component of the signal is recorded and used to judge the relative performance of the microphone. Figure 3 shows the relative performance between a standard and equalized microphone, both being pressured and depressurizing.

Standard Model 270-090 Microphone and Pressure Equallized Mirophone Performance vs. Line Pressure (Constant Power $450 \mathrm{~Hz}$ Generated Signal)

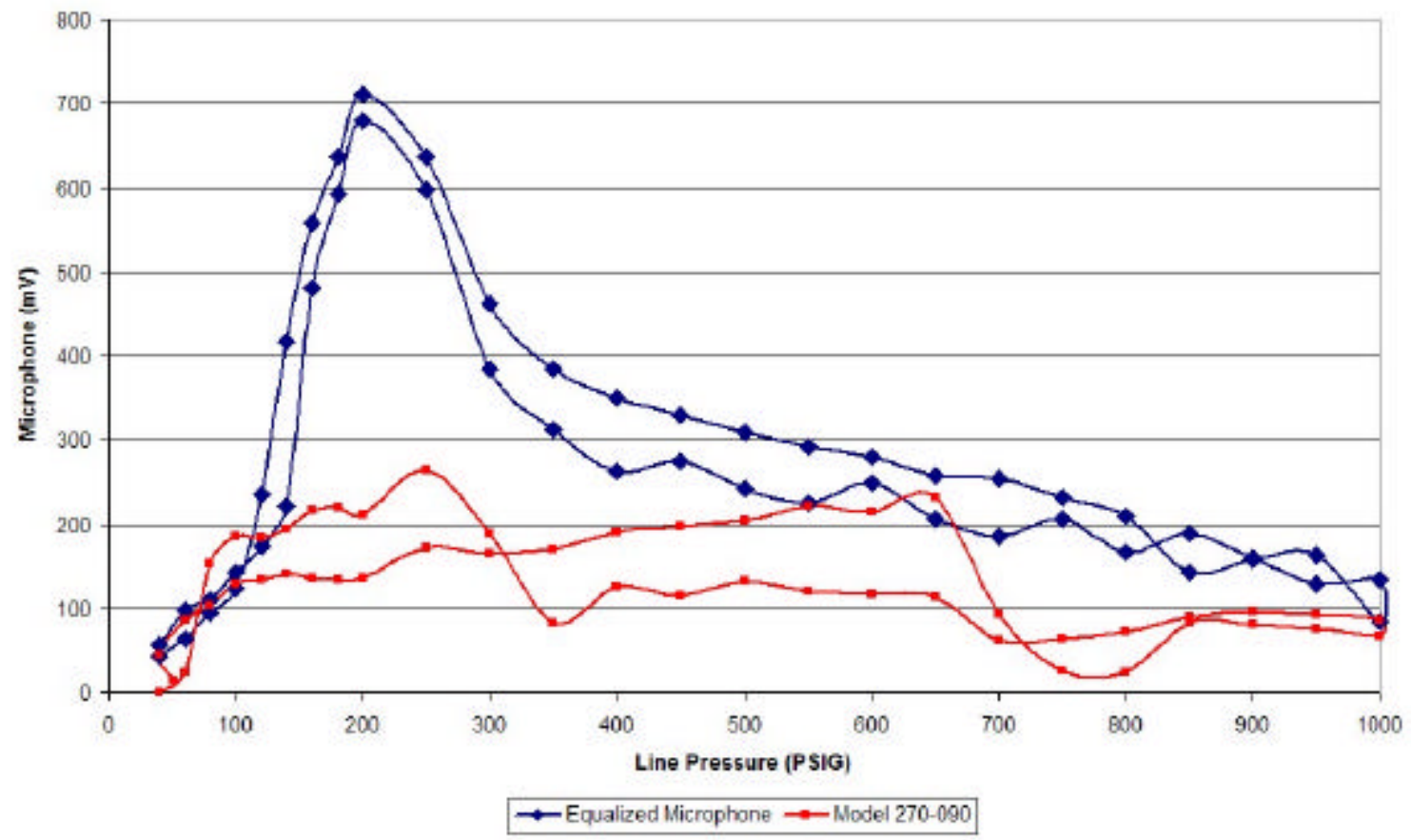

Figure 3 - Performance comparison between a Standard 270-090 microphone and a Pressure equalized version, both being exposed to the same power and frequency acoustic signal.

\section{B. Cataloging Data Acquisition and Management}

A recently completed survey of recent developments in the leak detection field indicated that Acoustic Systems Inc. (ASI) of Houston Texas appears to have made great strides recently with their WaveAlert system. In conducting a patent search for new developments, WVU's previous reports have been listed in the references cited section of US patent \# 6,668,619 B2 assigned to Acoustics Systems Inc. ASI uses acoustic pattern recognition systems for leak detection. Their pattern recognition 
systems use proprietary catalogs and local surveys of background acoustic signals as a baseline for comparison. This emphasizes the value of creating a catalog available for the public domain of background acoustic signals inside gas transmission lines.

To catalog the acoustic signals found in a natural gas transmission line a wide frequency range must be considered. The sampling rate needed for the higher frequency content of these signals was determined to be $44 \mathrm{kHz}$. At this high sampling rate the data files quickly reach the limits of computer data storage and analysis capabilities. This inability to deal with large data sets collected when cataloging led to the procurement of a new data acquisition system. The audio recording industry has a number of systems exactly for this purpose. These systems compress acoustic data files to a MP3 format. This allows the recording and efficient storage of very large acoustic data files. For example, 15 minutes of high resolution data $(44 \mathrm{kHz})$ can be store in as little as $32 \mathrm{Mb}$, compared with our original system where 30 seconds of relatively low resolution data $(4 \mathrm{kHz})$ consumed over $360 \mathrm{Mb}$ of space.

The TEAC TASCAM PS5 for the recording of acoustic signals. The unit is rugged and extremely portable. Along with its own battery power the units weighs only 1.5 lbs and is only 6" x 9" $\mathrm{x} 2$ "'.

Analog Audio Inputs (1) unbalanced with level control; (1) unbalanced" TS mic/line (switchable); (1) unbalanced"

TS mic (switchable to built-in mic)

Analog Audio Outputs (1) unbalanced" TRS stereo main; (1) 1.8" stereo headphone

Data Ports (1) USB; (1) MIDI In

Physical/Virtual Audio Tracks 4/0

Simultaneous Record/Play Channels 2/4

Tone Generator GM-compatible; 64-note polyphonic; 16-part multitimbral

Internal Data Format $44.1 \mathrm{kHz}, 24$-bit A/D/A Conversion $44.1 \mathrm{kHz}, 16$-bit

Storage Medium Compact Flash (3.3V, Type I; maximum 128 MB); maximum 60 minutes per card

Built-in Microphone condenser

Power 9 VAC adapter; (6) rechargeable NiMh AA batteries

Signal-to-Noise Ratio $87 \mathrm{~dB}$

Total Harmonic Distortion $0.01 \%$

Frequency Response $20 \mathrm{~Hz}-20 \mathrm{kHz}(+0.5 /-3.0 \mathrm{~dB})$

Display Backlit LCD; 2.28" (W) . 0.90" (H)

Dimensions 5.50" (W) . 8.50" (H) . 1.75" (D)

Weight $1.5 \mathrm{lb}$.

Table 1 - TEAC TASCAM PS5 specifications. (Broderson, S. , 2003) 

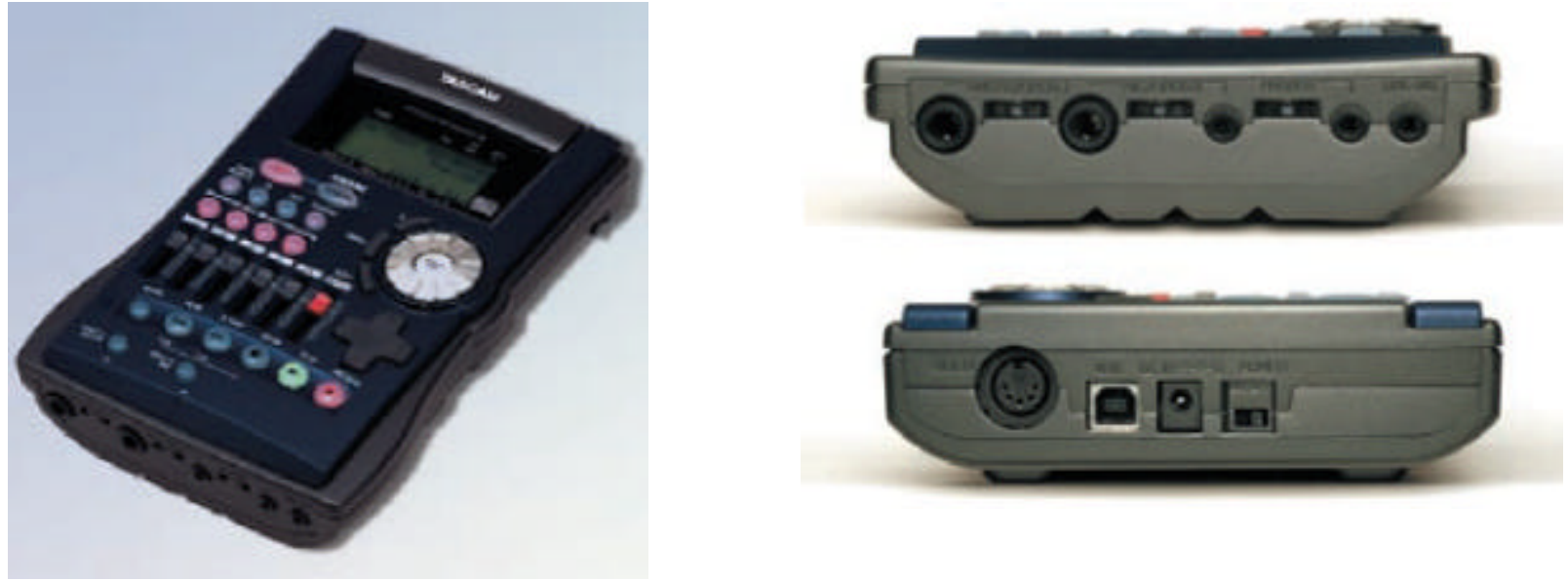

Figures 4 \& 5 - The Teac TASCAM PS-5 with audio inputs and outputs on the top. On the bottom are MIDI In, USB, and AC-adapter ports. Selector switches and the Compact Flash port are on the unit's right side. (Broderson, S., 2003)

A new signal-processing program capable of reading the compressed MP3 file format has been purchased and is currently being used for signal analysis. SIGVIEW is a complete real-time spectral analysis software package. This software has a wide range of powerful FFT spectral analysis tools, statistics functions and comprehensive visualization system. Real time data display, signal analysis and control Optimized FFT algorithm with fine parameter tuning are all built in. Time FFTs with powerful graphical solutions and parameter control, cross-spectral analysis and a real time signal calculator (subtract, multiply or add signals or analysis results, perform cross analysis) for fast data analysis. The program's statistics functions, graphical block diagram environment, custom tools and workspaces can be created and reused for dozens of signals. Signals can be combined and analyzed at the same time with no artificial limitations.

\section{Online Acoustic Sensor Calibrator (OASC)}

The complexity of the PAMP's sensing and recording equipment makes it desirable to conduct an online calibration at the beginning of field recording activities. Gas transmission line safety standards make it prohibitive to mount a signal generator and driver on the PAMP in the field because of the associated power and voltage required, therefore another signal generation device had to be found. Another design consideration is weight. An acoustic inline signal generator was developed using a precision-tuned, heavy bronze free-reed, double-checked to the A440 standard, which is mounted in an 1/8" copper tube. This instrument generates a specific acoustic signal depending on the gas flow through it. To limit the gas leakage rate, a valve and plug with a 0.040 inch diameter choke hole are installed downstream of the signal 
generator. The choked hole orifice determines the flow for a specific pressure. For a given pressure and flow the signal generator creates an acoustic signal with specific frequency and amplitude which can be measured with the PAMP instruments.

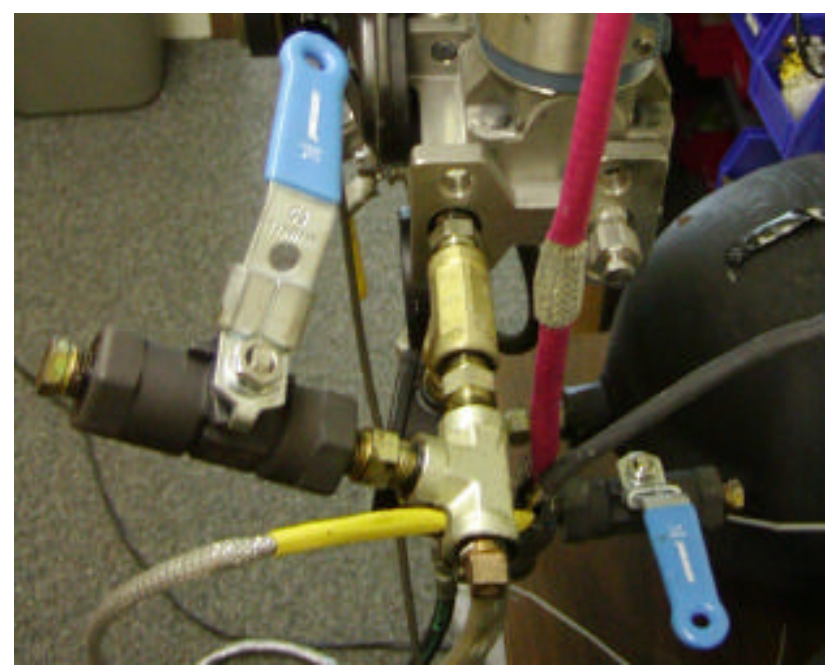

Figure 6 - Photograph of OASC installed on PAMP. Each of the blue handled valves are OASCs with different frequency-pressure curves.

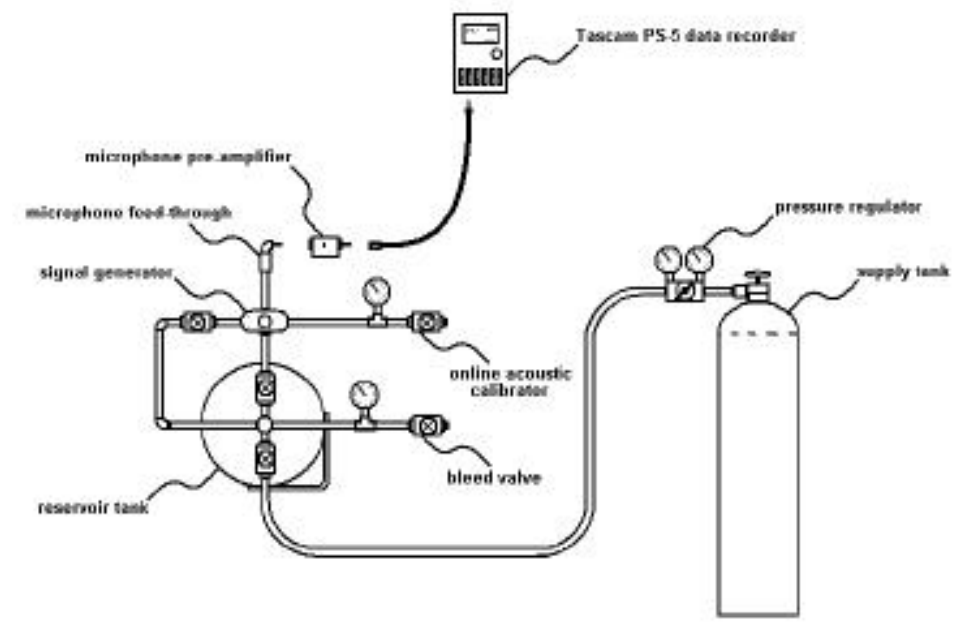

Figure 7 - Schematic of PAMP and the high-pressure laboratory apparatus

\section{Results and Discussion}


The pressure equalized Optimus 270-090 microphone as well as the standard 270-090 microphone were tested during compression up to line pressures of $1000 \mathrm{psi}$ and during decompression back down to atmospheric pressure. The microphones were mounted in their standard mounting locations in the PAMP. The PAMP was mounted onto a 3000-psi composite natural gas tank. The system was charged using a $200 \mathrm{lb}$ 2500 psi Nitrogen bottle. Figures 4 and 5 show the microphone response in both millivolts and $\mathrm{dB}$.

Mic Sensitivity in Pressurized Lines

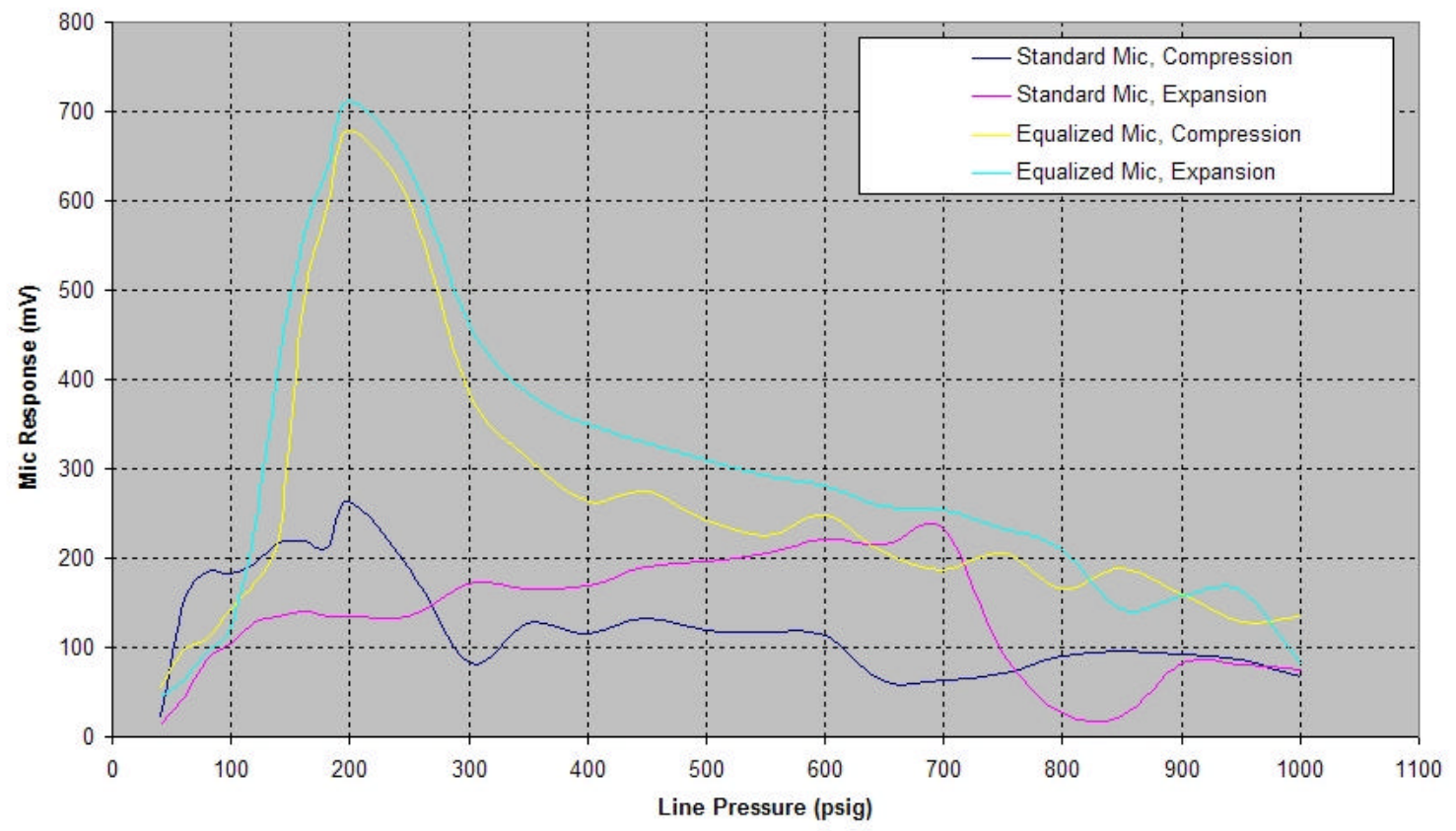

Figure 8- Equalized and standard Optimus 270-090 microphone frequency response in millivolts vs. line pressure in psig.

The microphone used has a minimum acoustic pressure level, $\mathrm{P}_{1}(\mathrm{~Pa})$, required to produce a measurable reference voltage, $\mathrm{V}_{1}(\mathrm{~V})$. At any time, the voltage output is proportional to the square root of the acoustic pressure. By using various calibrated acoustic sources, this reference voltage may be determined. For example, a $114 \mathrm{~dB}$ source will produce a specific output voltage, $\mathrm{V}_{2}(\mathrm{~V})$. By rearranging the following formula

to

$$
20 \log \left(\mathrm{V}_{2} / \mathrm{V}_{1}\right)=114 \mathrm{~dB}
$$

$$
\mathrm{V}_{1}=\mathrm{V}_{2} * 10^{(20 / 114)}
$$

the reference voltage $V_{1}$ can easily be found. Once several samples have been taken using various known $\mathrm{dB}$ source signals, $\mathrm{V} 1$ can be experimentally verified and then applied to any new output voltage to find its equivalent output in $\mathrm{dB}$. (Figure 8) 
Figures 9 through 11 show the PAMPS ability to accurately record specific acoustic signals. Figure 10 show a simulated leak noise over a generated $450 \mathrm{~Hz}$ signal. The $450 \mathrm{~Hz}$ signal is easily distinguish from the other signals. Sigview 1.9.1 can easily segregate the different frequency content from a variety of signal. By using compressed audio file formats a sampling rate of $44 \mathrm{kHz}$ is possible, which allows all of the relevant signal components to be analyzed and described.

Mic Sensitivity in Pressurized Line

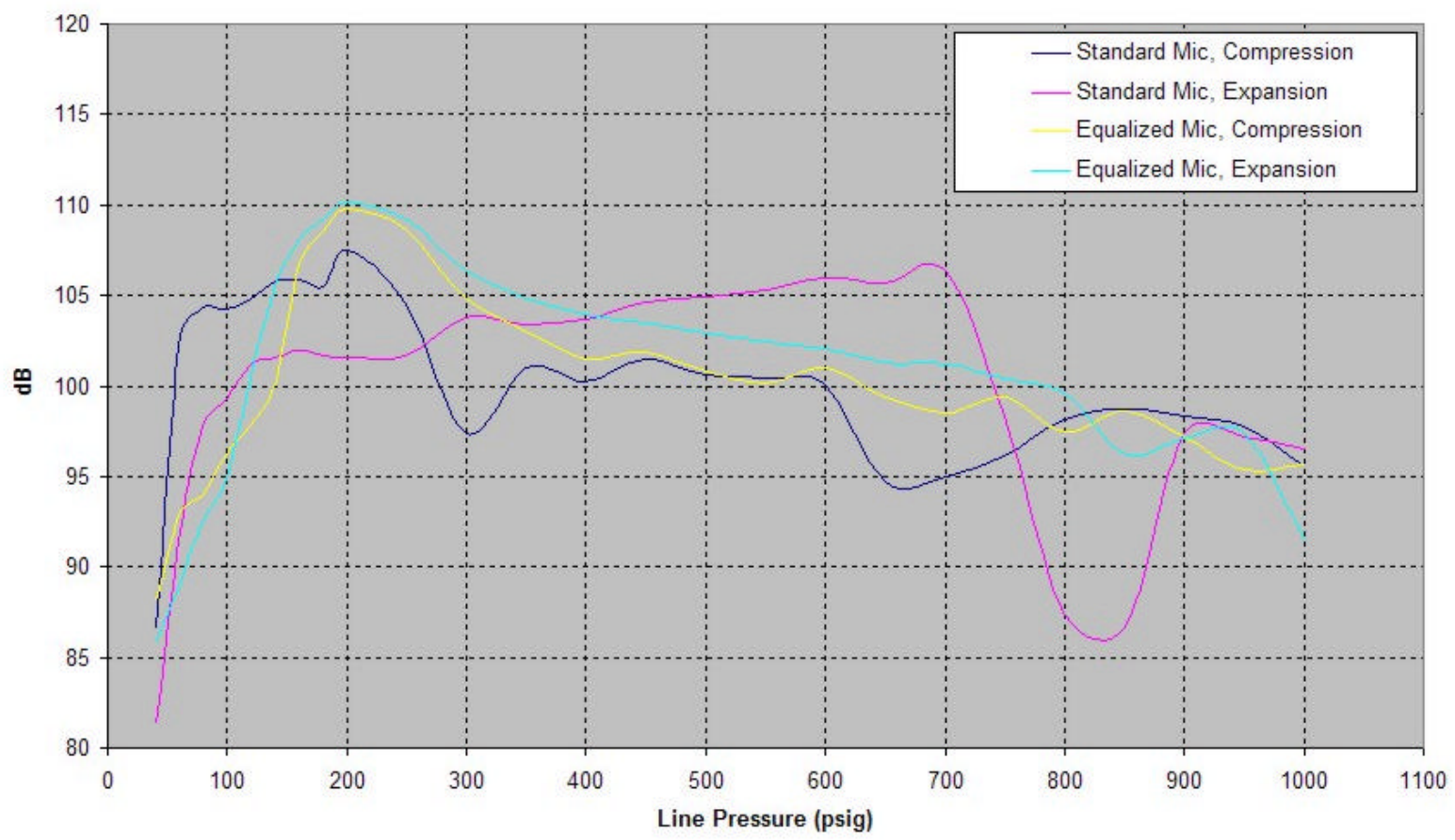

Figure 9 - Equalized and standard Optimus 270-090 microphone frequency response in decibels vs. line pressure in psig. 


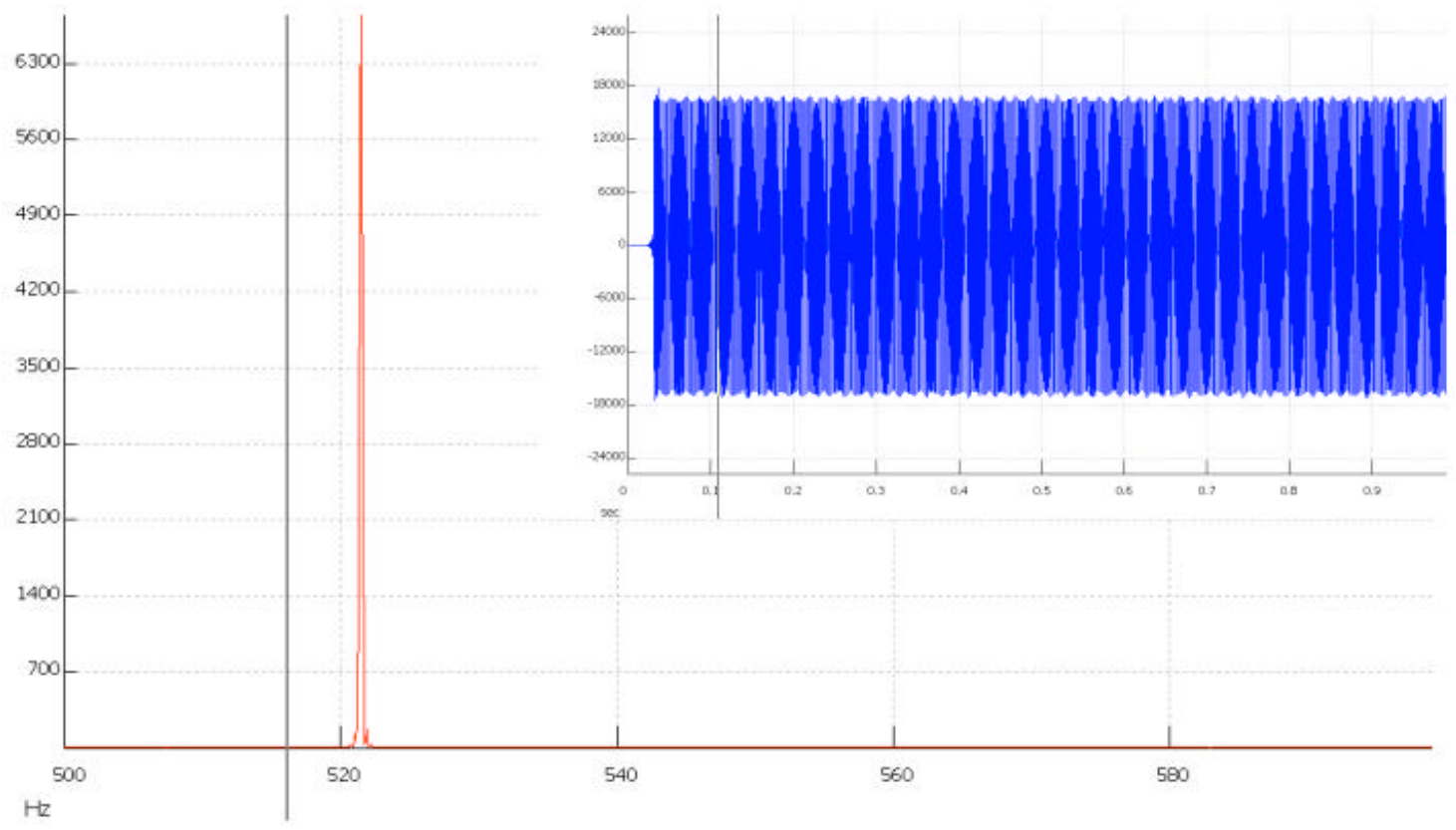

Figure 10 - FFT and raw signal of $521 \mathrm{~Hz}$ signal generated at a constant $350 \mathrm{psig}$ line pressure in Sigview 1.9.1 that has been recorded by the PAMP.

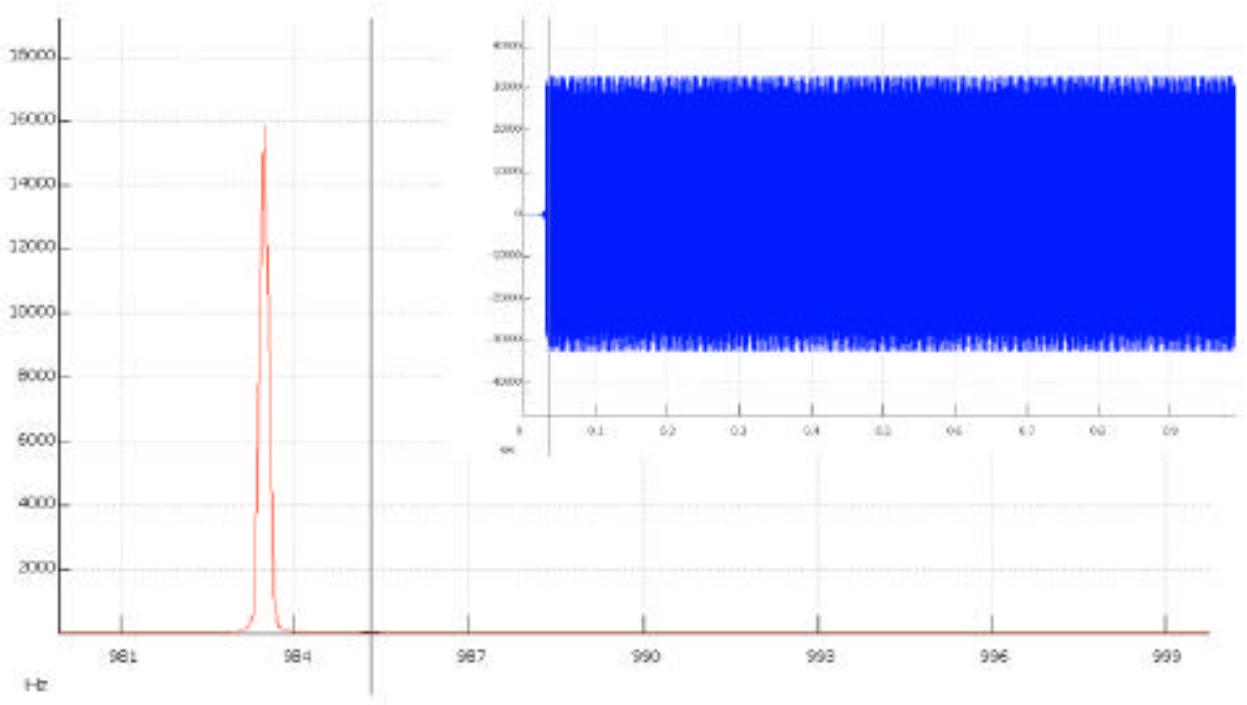

Figure 11 - FFT and raw signal of a $983 \mathrm{~Hz}, 114$ DB signal recorded by PAMP from a Textronix sound calibrator G in Sigview 1.9.1 that has been recorded by the PAMP for microphone calibration. 


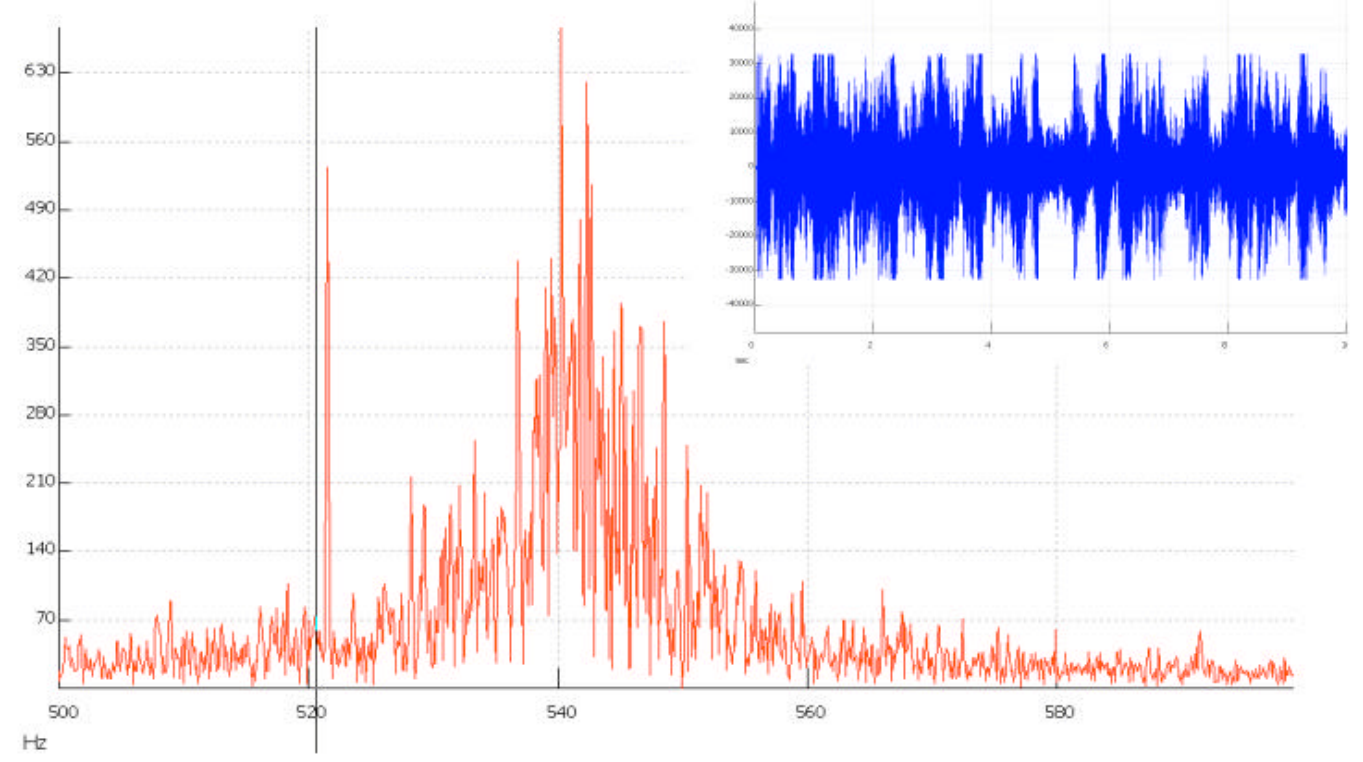

Figure 12 - FFT and raw signal of a $521 \mathrm{~Hz}$ signal generated at constant 350 psig line pressure with simulated leak (1/2" partially open valve) in Sigview 1.9.1 that has been recorded by the PAMP.

\section{Conclusions}

During previous field data collection a number of operational deficiencies in the PAMP were identified. These deficiencies have now been corrected. The achievements of this past quarter can be summarized as follows:

- A new pressure compensated microphone has been developed, which improves microphone sensitivity at higher pressures.

- A new data acquisition system, which compresses acoustic data, files to a MP3 format as used in the audio recording industry has been procured. This allows the recording and efficient storage of large acoustic data files.

- A new signal-processing program capable of reading the compressed file format has been purchased and is currently being used for signal analysis.

- An online acoustic calibration system has been developed and tested. Safety and field portability issues demanded that the generation of a known acoustic signal could not be accomplished by an electronic device that operated at more then $5 \mathrm{~V} \mathrm{DC}$. The system that has been designed uses the natural gas pressure to generate acoustic signals of known frequency and power for sensor calibration.

- A laboratory high-pressure (0-1000 psig) testing and calibration system has been developed for the PAMP.

The WVU PAMP if fully functional over the entire pressure range found in the natural gas transmission lines in this geographic region. Field portability and reliability have been greatly improved. Data collection and storage have also improved to the point were the full acoustic spectrum of acoustic signals to be cataloged can be accurately recorded and described. 


\section{Report Distribution:}

1) Electronic via CD-ROM in PDF Format, file name 41324R07.pdf Labeled:

DOE Award \# DE-FC26-01NT41324

$3^{\text {rd }}$ Quarter Report

West Virginia University

Dr. John Loth

304-293-4111 ext. 2343

2) One Paper Copy and the above CD-ROM

To:

NETL AAD Document Control BLDG. 921

U.S. Department of Energy

National Energy Technology Laboratory

P.O. Box 10940

Pittsburgh, PA 15236-0940 